CLINICAL STUDY

\title{
A variant of the IGF-I gene is associated with blood pressure but not with left heart dimensions at the age of 2 years: the Generation R Study
}

\author{
Vera A A van Houten ${ }^{1,2}$, Dennis O Mook-Kanamori ${ }^{1,2}$, Lennie van Osch-Gevers ${ }^{3}$, Eric A P Steegers ${ }^{4}$, \\ Albert Hofman ${ }^{2}$, Henriëtte A Moll ${ }^{3}$, Cornelia M van Duijn ${ }^{2}$, Willem A Helbing ${ }^{3}$, Anita C S Hokken-Koelega ${ }^{3}$ \\ and Vincent $W$ V Jaddoe ${ }^{1,2,3}$ \\ ${ }^{1}$ The Generation R Study Group (AE-006), Erasmus Medical Center, PO Box 2040, 3000 CA Rotterdam, The Netherlands, ${ }^{2}$ Department of Epidemiology, \\ Erasmus Medical Center, Rotterdam, The Netherlands, ${ }^{3}$ Department of Paediatrics, Erasmus Medical Center, Sophia Children's Hospital Rotterdam, The \\ Netherlands and ${ }^{4}$ Department of Obstetrics and Gynaecology, Erasmus Medical Center, Rotterdam, The Netherlands \\ (Correspondence should be addressed to VWV Jaddoe; Email: v.jaddoe@erasmusmc.nl)
}

\begin{abstract}
Background and objective: A common variant of the IGF-I gene has been shown to be associated with cardiovascular disease in adulthood. The objective of this study was to examine whether this variant of the IGF-I gene is associated with blood pressure and left heart dimensions in early childhood.

Research design and methods: This study was embedded in the Generation R Study, a population-based prospective cohort study from foetal life onwards. IGF-I promoter region was genotyped in DNA obtained from cord blood. Blood pressure (systolic and diastolic) and echocardiography (left ventricular mass, left atrial diameter and aortic root diameter) measurements were performed at the age of 2 years. Analyses were performed in 538 subjects.

Results: Eight alleles of the IGF-I promoter region were identified. In total, $43 \%$ of the subjects were homozygous for the 192 bp allele (wild type), 46\% were heterozygous and $11 \%$ were non-carriers. Significantly lower systolic and diastolic blood pressures were found in non-carrier subjects (difference compared with homozygous subjects: -4.4 (95\% confidence interval (CI) -7.8 to -1.1$) \mathrm{mmHg}$ and -3.5 (95\% CI: -6.9 to -0.1$) \mathrm{mm}$ respectively). No significant differences were found for left heart dimensions at the age of 2 years. No association was found when we used a previously proposed alternative classification of the IGF-I gene.

Conclusion: The variant type of the IGF-I promoter region is associated with lower blood pressure but not with left heart dimensions at the age of 2 years. Follow-up studies are needed to examine whether these differences persist in later life.
\end{abstract}

European Journal of Endocrinology 159 209-216

\section{Introduction}

Insulin and insulin-like growth factors (IGF-I and IGF-II) are the most important growth factors for foetal and early postnatal growth $(1,2)$. Changes in circulating levels of these growth factors are also associated with several diseases in adulthood $(2,3)$. Previously, it has been suggested that higher IGF-I levels are associated with increased left ventricular mass and geometry in subjects with essential hypertension (4). Decreased circulating IGF-I levels have been found to be directly associated with hypertension in adults (5). Moreover, low IGF-I levels are also associated with an increased risk of cardiovascular disease, such as ischaemic heart disease (6-8).

IGF-I is encoded by the IGF-I gene. A common variant in the promoter region of this gene has been identified and extensively investigated over the past decade.
Previous studies have suggested that non-carriage of the $192 \mathrm{bp}$ variant of this IGF-I promoter region polymorphism is associated with decreased circulating IGF-I levels in adulthood (9). This variant has also been demonstrated to be associated with cardiovascular disease, type 2 diabetes and variation in growth characteristics, including birth size and final height in adulthood, in the normal population (9-15). It was also suggested that non-carriage of the 192/194 bp alleles was associated with cardiovascular disease (16-19).

Thus, several studies showed associations between a common IGF-I promoter region polymorphism and low circulating IGF-I levels, and subsequently the development of cardiovascular disease in adulthood $(13,14$, 16-19). We hypothesized that this IGF-I promoter region polymorphism already influences the development of blood pressure and left heart dimensions in early childhood. Therefore, we examined, in 538 children 
participating in a prospective cohort study, the associations of this IGF-I promoter region polymorphism with blood pressure and left heart dimensions at the age of 2 years.

\section{Patients and methods}

\section{Design}

This study was embedded in the Generation R Study, a population-based prospective cohort study from foetal life onwards. This study is designed to identify early environmental and genetic determinants of growth, development and health from foetal life until young adulthood and has previously been described in detail (20, 21).

All children were born between April 2002 and January 2006 and form a prenatally recruited birth cohort that is currently being followed until young adulthood. Of all eligible children, $61 \%$ participated in the study at birth. Assessments in pregnancy included physical examinations, foetal ultrasounds, biological samples and questionnaires. Additional, more detailed assessments of foetal and postnatal growth and development were conducted in a subgroup, referred to as the Generation R Focus Cohort. This subgroup is ethnic homogeneous to exclude possible confounding or effect modification by ethnicity. Of all approached women, $80 \%$ was enrolled in this subgroup study in late pregnancy (gestational age of 30 weeks). For the present study, postnatal follow-up examinations were performed at the age of 2 years.

The study has been approved by the Medical Ethics Committee of the Erasmus Medical Centre, Rotterdam. Written informed consent was obtained from all participants or their parents.

\section{Cohort for analysis}

In total, 1232 women were enrolled in the Generation $\mathrm{R}$ Focus Study during pregnancy. Twin pregnancies $(n=15)$ and pregnancies leading to perinatal death $(n=2)$ were excluded from the present analysis. Of the remaining singleton 1215 live births, DNA for IGF-I genotyping was available in $61 \%(n=738)$ of the subjects. Of these genotyped children, 538 (73\%) subjects participated in the follow-up examination at the age of 2 years. Blood pressure was measured in $68 \%(n=365)$ and echocardiograms were performed in $83 \%(n=448)$ of these infants during the examination at the age of 2 years. Missing blood pressure measurements or echocardiograms were mainly due to crying behaviour or logistic constraints.

\section{Genotyping}

DNA was collected from cord blood samples of the children at birth. Cord blood for DNA isolation was available in $85 \%$ of all children participating in the Focus Cohort. Missing cord blood samples was mainly due to logistic constraints at delivery. For the IGF-I gene, PCR was performed using oligonucleotide primers designed to amplify the polymorphic cytosine-adenine repeat $1 \mathrm{~kb}$ upstream of the human IGF-I gene and has previously been described in detail $(12,22)$. Eight different alleles of the IGF-I promoter region were identified. The allele distribution is based on two alleles per infant. As in previous studies, IGF-I genotypes were first categorized in the following categories based on the most common allele of this IGF-I gene promoter polymorphism: homozygous $192 \mathrm{bp}$ (wild type) and heterozygous $192 \mathrm{bp}$ and non-carrier (10, 11, 23-25). The genotype distribution was similar to those found in previous studies and the frequency distribution did not deviate from the Hardy-Weinberg equilibrium $\left(\chi^{2}=0.005, P>0.9\right)(10,13,25)$. We also categorized the IGF-I genotypes based on their 192 and $194 \mathrm{bp}$ alleles, as described in studies demonstrating associations with cardiovascular disease $(15,16,19,26)$. These categories are based on the presence or absence of the following genotypes: 192/192, 194/194, 192/194 and $194 / 192 \mathrm{bp}$. The distribution of this stratification was similar to those found in previous studies $(15,16)$. In our study, IGF-I levels were not available due to logistical and financial constraints.

\section{Blood pressure and left heart dimensions}

Systolic blood pressure (SBP) and diastolic blood pressure (DBP) were measured twice to the nearest mmHg at the left upper arm by using an automatic sphygmomanometer (Vital Signs Monitor CAS 740, CAS Medical Systems, Inc., Branford, Connecticut, USA (27)). The child was seated quietly during the measurements and a cuff was selected with a cuff width $\sim 40 \%$ of the arm circumference and long enough to cover $90 \%$ of the arm circumference (28). The mean of the two readings was used for the data analysis. In 122 children, it was not possible to measure blood pressure twice due to crying and oppositional behaviours. Thus, their blood pressure was based on one measurement. Mean arterial pressure (MAP) was computed using the following formula: $\mathrm{MAP}=\mathrm{DBP}+1 / 3 \times(\mathrm{SBP}-\mathrm{DBP})$.

Two-dimensional and M-mode echocardiograms were performed on Advanced Technology Laboratories (ATL) 5000 ultrasound system in the children at the age of 2 years. The examination was carried out in a quiet room with the child quietly awake in supine position. In a parasternal long-axis view, left ventricular end diastolic diameter (LVEDD), interventricular septal thickness (IVST), left ventricular posterior wall thickness (LVPWT), left atrial diameter and aortic root diameter were measured using methods recommended by the American Society of Echocardiography (29). Left ventricular mass was computed by using the formula derived by Devereux et al. (30): left ventricular mass $=0.80 \times 1.04$ 
$\left((\text { IVST + LVEDD + LVPWT })^{3}-(\text { LVEDD })^{3}\right)+0.6$. Left ventricular volume (end diastolic) was calculated using Teichholz formula (31): left ventricular volume $=(7 \times$ $\left.\mathrm{LVEDD}^{3}\right) /(2.4+\mathrm{LVEDD})$, so that the ratio between left ventricular mass and left ventricular volume could be derived. Left ventricular mass-volume ratio and relative wall thickness (RWT) indicate concentricity of left ventricular hypertrophy (30). RWT was obtained through the formula $(2 \times($ LVPWT/LVEDD) $)(32)$.

One echocardiographer performed the vast majority $(86 \%)$ of these measurements. Two other echocardiographers performed the other measurements.

\section{Covariates}

All anthropometrics in the infants were measured without clothes at the same visits as the blood pressure and echocardiogram measurements. Weight was measured to the nearest gram using a mechanical scale and length was measured in standing position using a Harpenden Stadiometer. Birth weight, date of birth and gender were obtained from midwife and hospital registries. Maternal smoking habits were assessed in each questionnaire. Information about duration of breastfeeding was obtained by postnatal questionnaires at the ages of 2, 6 and 12 months.

\section{Data analysis}

First, differences of child characteristics between the heterozygous $192 \mathrm{bp}$ or non-carriers and homozygous 192 bp IGF-I genotype groups were assessed by the independent sample $t$-test for continuous variables and the $\chi^{2}$-test for categorical variables. Intra-subject variation in those children with two blood pressure measurements was assessed by the paired sample $t$-test.

Subsequently, we performed multiple linear regression models to assess the associations of the IGF-I genotype groups with blood pressure (SBP, DBP and MAP), left ventricular mass, left atrial diameter, aorta root diameter and left ventricular volume at the age of 2 years. The models were adjusted for gender, gestational age, current age and the number of blood pressure measurements (model 1) and additionally adjusted for current weight and height (model 2). We additionally adjusted these models for maternal smoking habits and breastfeeding. Since our effect estimates were not influenced and the models did not improve after these adjustments, we did not include these last two covariates in the further analyses and results. Instead of just weight, we also included weight gain between birth and 2 years (in absolute numbers) and SDS weight gain, separately, in our models. Our effect estimates did not materially change after the adjustments and therefore we did not use these in the further analysis and results. Furthermore, we performed similar models for the left ventricular mass-volume ratio and the RWT to identify concentric left ventricular hypertrophy.

Finally, we performed the same multiple linear regression models to assess the associations with blood pressure (systolic and diastolic) and left ventricular mass, using an alternative classification for the genotype groups (the presence or absence of 192/194 bp).

All measures of association are presented with their 95\% confidence intervals (CIs). Statistical analyses were performed using the Statistical Package of Social Sciences version 11.0 for Windows (SPSS, Inc., Chicago, IL, USA).

\section{Results}

Subject characteristics for the three IGF-I genotype groups are shown in Table 1. Of all children participating in the follow-up measurements at 2 years of age, 230 (43\%) subjects were 192 bp homozygous, 247 (46\%) subjects were $192 \mathrm{bp}$ heterozygous and 61 (11\%) subjects were non-carriers. Compared with the 192 bp homozygous carriers, SBP, DBP and MAP were lower in the non-carrier group. Except for the age at the follow-up measurement, no other significant differences were found in the subject characteristics between the three genotypes. The differences between the first and second blood pressure measurements, in those children with two measurements, was $-0.2(95 \% \mathrm{CI}$ : $-1.3,0.9)$ $\mathrm{mmHg}$ for SBP and -0.5 (95\% CI: $-1.7,0.7) \mathrm{mmHg}$ for DBP and not significant. No significant differences were found between the SBP and DBP based on one and two measurements (difference in SBP: -2.1 (95\% CI: -4.5 , $0.3) \mathrm{mmHg}$; DBP: -1.2 (95\% CI: $-3.3,1.0) \mathrm{mmHg})$.

Table 2 shows the adjusted differences of blood pressure among the three genotypes. These multiple linear regression models were adjusted for gender, gestational age, current age and the number of blood pressure measurements (model 1) and additionally adjusted for current weight and height (model 2). SBP, DBP and MAP at 2 years of age were significantly lower among the non-carrier subjects compared with the homozygous group (difference: -4.4 (95\% CI: -7.8 to $-1.1) \mathrm{mmHg},-3.5$ (95\% CI: -6.9 to -0.1$) \mathrm{mmHg}$ and -3.8 (95\% CI: -6.9 to -0.7$) \mathrm{mmHg}$ respectively). SBP was also significantly lower in the heterozygous compared with the homozygous 192 bp allele subjects (difference: -2.3 (95\% CI: -4.3 to -0.2$) \mathrm{mmHg}$ ). Table 3 shows the adjusted differences of left heart dimensions among the three genotypes. These multiple linear regression models were adjusted for gender, gestational age, current age (model 1) and additionally adjusted for current weight and height (model 2). No significant differences were found among the three IGF-I genotype groups and left heart dimensions. Nor was IGF-I genotype associated with left ventricular mass-volume ratio or the RWT (Table 3). 
Table 1 Subject characteristics $(n=538)$ at birth and at 2 years of age, according to the insulin-like growth factor-I (IGF-I) genotype.

\begin{tabular}{|c|c|c|c|}
\hline & $\begin{array}{l}\text { Homozygous } 192 \text { bp } \\
\text { allele }(n=230)\end{array}$ & $\begin{array}{l}\text { Heterozygous } 192 \text { bp } \\
\text { allele }(n=247)\end{array}$ & $\begin{array}{l}\text { Non-carrier } 192 \text { bp } \\
\text { allele }(n=61)\end{array}$ \\
\hline \multicolumn{4}{|l|}{ Birth } \\
\hline Birth weight $(\mathrm{g})$ & $3534(460)$ & $3563(519)$ & $3617(412)$ \\
\hline Gestational age (weeks) & $40.1(36.4-42.4)$ & $40.3(37.3-42.5)$ & $40.6(36.3-42.5)$ \\
\hline Gender (\% boys) & $56.1 \%$ & $47.0 \%$ & $59.0 \%$ \\
\hline \multicolumn{4}{|l|}{2 years } \\
\hline Age at visit (months) & $25.3(23.5-28.7)$ & $25.0(23.7-28.0)^{\star}$ & $25.1(23.6-28.6)$ \\
\hline Weight $(\mathrm{g})$ & $12815(1470)$ & $12580(1353)$ & $12793(1520)$ \\
\hline Length $(\mathrm{cm})$ & $89.1(3.1)$ & $88.8(3.2)$ & $89.3(3.4)$ \\
\hline Systolic blood pressure $(\mathrm{mmHg})$ & $103(9.7)$ & $101(9.4)^{\star}$ & $98(8.8)^{\dagger}$ \\
\hline Diastolic blood pressure (mmHg) & $63(9.7)$ & $62(10.0)$ & $60(8.3)^{*}$ \\
\hline Mean arterial pressure $(\mathrm{mmHg})$ & $77(8.8)$ & $75(9.1)$ & $73(7.8)^{*}$ \\
\hline \multicolumn{4}{|l|}{ Left heart dimensions } \\
\hline Left ventricle mass $(\mathrm{g})$ & $31.4(5.3)$ & $31.0(5.7)$ & $31.2(6.0)$ \\
\hline Left atrial diameter (mm) & $20.5(2.4)$ & $20.8(2.4)$ & $20.8(2.4)$ \\
\hline Aortic root diameter (mm) & $16.3(1.6)$ & $16.3(1.3)$ & $16.3(1.8)$ \\
\hline Left ventricular volume (ml) & $6.5(1.0)$ & $6.4(1.0)$ & $6.5(1.0)$ \\
\hline Left ventricular mass-volume ratio $(\mathrm{g} / \mathrm{ml})$ & $4.9(0.9)$ & $4.9(0.9)$ & $4.9(0.9)$ \\
\hline Relative wall thickness & $0.3(0.1)$ & $0.3(0.1)$ & $0.3(0.1)$ \\
\hline
\end{tabular}

${ }^{\star} P$ value $<0.05,{ }^{\dagger} P$ value $<0.01$ versus reference group (homozygous $192 \mathrm{bp}$ ). Differences were tested using the independent sample $t$-test and $\chi^{2}$-test Values are means (SDS) or medians (95\% range) for variables with skewed distribution. Of the total group, data were missing of postnatal follow-up of weight $(n=42)$, length $(n=58)$, systolic blood pressure $(n=173)$, diastolic blood pressure $(n=173)$, mean arterial pressure $(n=173)$, left ventricular mass $(n=114)$, left atrium diameter $(n=92)$ and aortic root diameter $(n=93)$, left ventricular volume $(n=109)$, left ventricular mass-volume ratio $(n=114)$ and relative wall thickness $(n=110)$.

Table 4 shows the estimated differences using the alternative classification for genotype groups, analysed by multiple linear regression models as described above. Classification of the IGF-I gene promoter polymorphism based on the presence or absence of the 192/192, 194/ $194,192 / 194$ or $194 / 192$ bp genotypes showed that these genotypes were present in $358(72 \%)$ subjects and absent in $153(28 \%)$ subjects. We found no association of the IGF-I gene with SBP, DBP and left ventricular mass at 2 years of age.

\section{Discussion}

We hypothesized that a common genetic variant of the IGF-I promoter region was associated with blood pressure and left heart dimensions at the age of
2 years. SBP, DBP and MAP at this age were lowest among the non-carrier subjects. We did not find any association between genotype groups and left heart dimensions at 2 years of age. No associations were found when we used a previously proposed alternative classification of the IGF-I gene.

To our knowledge, this study is the first prospective cohort that examined the association of an IGF-I gene promoter polymorphism with blood pressure and left heart dimensions in early childhood. Genotyping was successful for IGF-I promoter region in 738 children of the Generation R Focus Cohort. Of these children, 230 (73\%) subjects homozygous for the $192 \mathrm{bp}$ allele, 247 (74\%) subjects heterozygous for the 192 bp allele and $61(70 \%)$ non-carriers for the $192 \mathrm{bp}$ allele, participated in the follow-up measurement at 2 years of age. Children from which the IGF-I genotype was unknown

Table 2 Differences in blood pressure, according to insulin-like growth factor-I (IGF-I) genotype with the homozygous 192 bp group as reference group.

\begin{tabular}{|c|c|c|c|}
\hline Genotype & SBP $(\mathrm{mmHg})$ & DBP $(\mathrm{mmHg})$ & Mean arterial pressure $(\mathrm{mmHg})$ \\
\hline \multicolumn{4}{|l|}{ Model 1} \\
\hline Homozygous 192 bp & Reference & Reference & Reference \\
\hline Heterozygous 192 bp & $-2.5(-4.5,-0.4)^{*}$ & $-1.7(-3.9,0.4)$ & $-2.0(-3.9,-0.0)^{\star}$ \\
\hline Non-carriers 192 bp & $-4.6(-7.9,-1.4)^{\dagger}$ & $-3.5(-6.9,-0.1)^{\star}$ & $-3.9(-6.9,-0.8)^{\star}$ \\
\hline \multicolumn{4}{|l|}{ Model 2} \\
\hline Homozygous 192 bp & Reference & Reference & Reference \\
\hline Heterozygous 192 bp & $-2.3(-4.3,-0.2)^{*}$ & $-1.4(-3.5,0.8)$ & $-1.7(-3.6,0.3)$ \\
\hline Non-carriers 192 bp & $-4.4(-7.8,-1.1)^{\dagger}$ & $-3.5(-6.9,-0.1)^{*}$ & $-3.8(-6.9,-0.7)^{\star}$ \\
\hline
\end{tabular}

${ }^{\star} P$ value $<0.05,{ }^{\dagger} P$ value $<0.01$ versus reference group (homozygous $192 \mathrm{bp}$ ). SBP, systolic blood pressure; DBP, diastolic blood pressure. Values are differences (95\% confidence interval). Differences are based on multiple linear regression models adjusted for gender, gestational age, current age and the number of measurements (model 1) and additionally adjusted for current weight and height (model 2). Analyses are based on the following numbers: homozygous $192 \mathrm{bp}, n=156(43 \%)$; heterozygous $192 \mathrm{bp}, n=192(46 \%)$ and non-carriers, $192 \mathrm{bp}, n=41(11 \%)$. 


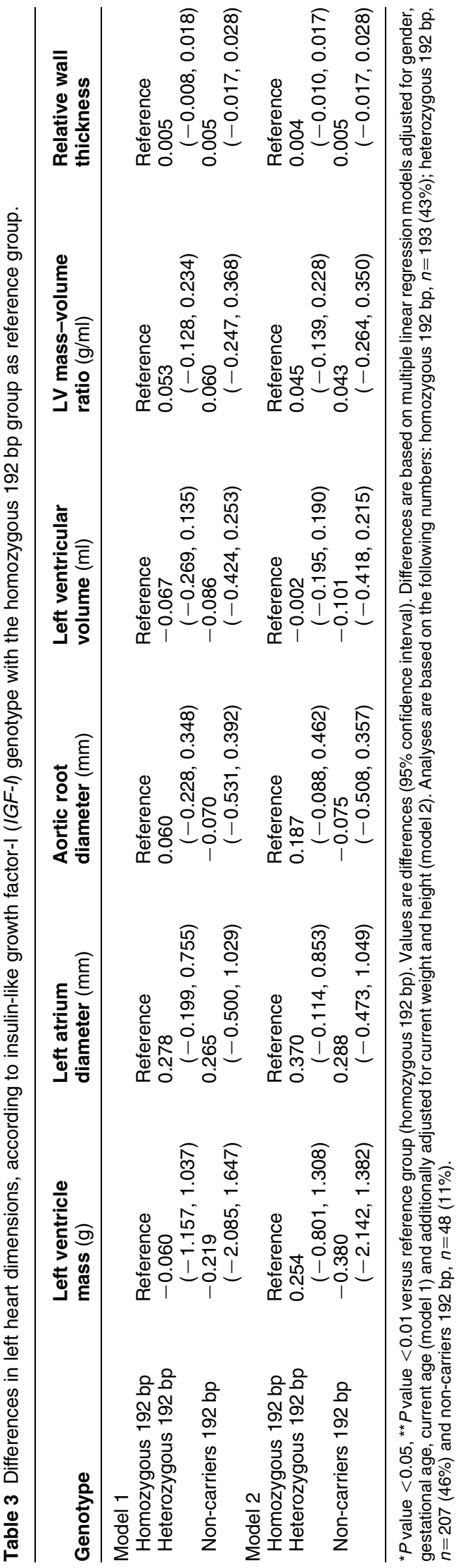

had a shorter gestational age (difference: $-0.34(95 \%$ CI: $-0.55,-0.12)$ weeks, $P=0.002)$ and were lighter at birth (difference: $-70.0(95 \%$ CI: $-146.6,6.7) \mathrm{g}$, $P=0.074)$ than subjects who were genotyped. Our effect estimates would be biased if the associations between genotype and cardiovascular outcomes differ between those with and without complete data. This seems unlikely but cannot be excluded. No differences were found in birth characteristics between IGF-Igenotyped children with and without follow-up measurements at the age of 2 years.

Blood pressure measurements at 2 years of age were available in $68 \%$ of the children who were genotyped for IGF-I and missing values were similar across the three genotype groups. No differences were found in birth and postnatal growth characteristics between the children with and without blood pressure measurements. Although we followed a strict protocol, it was not possible to measure blood pressure twice in 122 out of the 365 children, thus their blood pressure was based on one measurement. This may lead to selection bias, but no significant differences were found between the SBP and DBP based on one and two measurements. The genotype distribution also did not differ between those infants with one measurement and those in which the blood pressure was measured twice. Not all blood pressure measurements were taken at the same time of the day, although all of them were measured during office hours (0900-1700 h). We do not think that this will bias our results, because studies of ambulatory blood pressure measurements in young children showed a small variation in blood pressure during day time and only a slight nocturnal decrease $(33,34)$. In total, $83 \%$ of the children who were genotyped for IGF-I underwent a postnatal echocardiogram. This may lead to a loss of power and underestimation of the effects of genotype on blood pressure and left heart dimensions in early childhood. The relatively small amount of studied children in our study is a limitation. These missing values would bias our results if the associations of the IGF-I gene promoter region polymorphism with blood pressure and left heart dimensions would differ between those included and not included in this study. This seems unlikely but cannot be excluded. Furthermore, to our knowledge, our study is the largest examining these associations in young children.

Over the past decade, several studies have demonstrated associations of the promoter region of the IGF-I gene with the human cardiovascular system and also with the metabolic phenotype and growth in childhood and adults $(9-19,25)$. An increased risk of mortality was found in patients after myocardial infarction, in those who were variant carriers of the IGF-I polymorphism (19). The same results were found for subjects with type 2 diabetes, who developed a myocardial infarction (15). An increased risk of incident heart failure in subjects aged 55-75 years, who were noncarriers of the $192 \mathrm{bp}$ allele was found as well (16). 
Table 4 Differences in blood pressure and left ventricular mass, according to insulin-like growth factor-I (IGF-I) genotype with the presence of $192 / 194 \mathrm{bp}$ versus the absence of $192 / 194 \mathrm{bp}$.

\begin{tabular}{llll}
\hline Genotype & SBP $(\mathrm{mmHg})$ & DBP $(\mathrm{mmHg})$ & Left ventricular mass $(\mathrm{g})$ \\
\hline $192 / 194 \mathrm{bp} \mathrm{present}^{\mathrm{a}}$ & Reference & Reference & Reference \\
$192 / 194 \mathrm{bp} \mathrm{absent}^{\mathrm{b}}$ & $0.6(-1.7,3.0)$ & $0.4(-2.1,2.8)$ & $-0.3(-1.4,0.9)$ \\
\hline
\end{tabular}

Values are differences (95\% confidence interval). Differences are based on multiple linear regression models adjusted for gender, gestational age, current age, current weight and height. SBP, systolic blood pressure; DBP, diastolic blood pressure.

aPresent: presence of the following combination of genotypes: 192/192, 194/194, 192/194 or 194/192 bp ( $n=358)$.

${ }^{\mathrm{b}}$ Absent: all the other IGF-I genotypes $(n=153)$.

All these studies were conducted in adults. Genetic variants may be stronger related to blood pressure and left heart dimensions in early life than in adulthood when life style habits seem to be more important determinants. Therefore, we expected that these polymorphisms were associated with blood pressure and left heart dimensions in early childhood. Prior to the study, we had hypothesized that non-carriers would have a higher blood pressure in childhood.

Unexpectedly, we found non-carrier subjects to have a lower SBP and DBP than homozygous 192 bp subjects. We are not aware of any other studies reporting a lower blood pressure in non-carrier subjects for this polymorphism. However, previous association studies are scarce and have not been conducted in children. In vitro and in vivo experiments showed that IGF-I causes vasodilatation $(5,35)$. The IGF-I promoter region polymorphism has shown to be associated with IGF-I levels in adults (9). However, IGF-I levels vary from childhood to adulthood. Peak levels are generally seen in puberty $(36,37)$. We might speculate that variation in IGF-I levels during postnatal life and thereby this polymorphism, have different biological effects at different ages. Unfortunately, IGF-I levels were not measured in the present study. Another explanation for the discrepancy between our and previous findings may be that these previous reports, showing associations of non-carriers with increased cardiovascular disease, actually develop during postnatal life due to interactions between this genetic variant with various postnatal life style factors. However, our finding could also be due to chance. Further studies focused on the association of this genetic variant with blood pressure are definitely needed.

We did not find an association with blood pressure and left ventricular mass after stratifying the IGF-I genotype differently (Table 4). This result might be explained by the fact that the mean blood pressure in children with the 194/194 bp genotype was lower than in the 192/192 and 192/194 bp groups. This difference was not significant, due to the small number of children in the 194/194 bp group $(n=12)$. This might lower the mean blood pressure of the whole reference group, in which the 194/194 bp genotype is included, and explain the small non-significant difference found in the analysis.
We did not find associations for IGF-I genotype and left heart dimensions at 2 years of age. Since blood pressure is associated with IGF-I at 2 years of age, we also expected an association with left heart dimensions at this age. IGF-I has been shown to be an important growth factor of the heart in adults and an increased IGF-I protein expression was found in humans with left ventricular hypertrophy $(38,39)$. Differences between genotype groups in cardiac structures may develop at older age in childhood and adulthood or the IGF-I polymorphism may interact with postnatal growth or environmental factors and thereby increase the risk of cardiovascular disease. This could explain the lack of associations with left heart dimensions at this age. Alternatively, the current study could be too small to show these differences. However, we did not find consistent tendencies that we expect to become stronger or significant in a larger cohort.

In conclusion, our findings demonstrated an association of the IGF-I genotype variants with SBP and DBP, but not with left heart dimensions, at the age of 2 years. We believe that our results should primarily be considered as hypothesis generating rather than as real causal association. Future studies relating this and other common genetic variants of the IGF-I gene to IGF-I levels and blood pressure and/or cardiac structures are needed for replication. We will perform follow-up studies to examine whether these effects persist in later life. Systematic searches for diseaseassociated common variants by means of genome-wide association studies may enable us to obtain a more complete understanding of the functionality of the entire IGF-I region in relation to development of cardiovascular risk factors.

\section{Acknowledgements}

The Generation R Study was conducted by the Erasmus Medical Center in close collaboration with the School of Law and Faculty of Social Sciences of the Erasmus University Rotterdam, the Municipal Health Service Rotterdam area, Rotterdam, the Rotterdam Homecare Foundation, Rotterdam and the Stichting Trombosedienst \& Artsenlaboratorium Rijnmond (STAR), Rotterdam. We gratefully acknowledge the contribution 
of general practitioners, hospitals, midwives and pharmacies in Rotterdam. The first phase of the Generation R Study is made possible by financial support from the Erasmus Medical Center, Rotterdam, the Erasmus University Rotterdam and the Netherlands Organization for Health Research and Development (ZonMw). The study described in this paper was made possible by an additional grant from the National Diabetic Fund (grant no. 2100.0074).

\section{References}

1 Laron Z. Insulin-like growth factor 1 (IGF-1): a growth hormone. Molecular Pathology 200154 311-316.

2 Laron Z. IGF-1 and insulin as growth hormones. Novartis Foundation Symposium 2004262 56-77 (discussion 77-83, 265-268).

3 Accili D, Nakae J, Kim JJ, Park BC \& Rother KI. Targeted gene mutations define the roles of insulin and IGF-I receptors in mouse embryonic development. Journal of Pediatric Endocrinology and Metabolism 199912 475-485.

4 Verdecchia P, Reboldi G, Schillaci G, Borgioni C, Ciucci A, Telera MP, Santeusanio F, Porcellati C \& Brunetti P. Circulating insulin and insulin growth factor-1 are independent determinants of left ventricular mass and geometry in essential hypertension. Circulation $19991001802-1807$.

5 Hunt KJ, Lukanova A, Rinaldi S, Lundin E, Norat T, Palmqvist R, Stattin P, Riboli E, Hallmans G \& Kaaks R. A potential inverse association between insulin-like growth factor I and hypertension in a cross-sectional study. Annals of Epidemiology $2006 \mathbf{1 6} 563-571$.

6 Juul A, Scheike T, Davidsen M, Gyllenborg J \& Jorgensen T. Low serum insulin-like growth factor I is associated with increased risk of ischemic heart disease: a population-based case-control study. Circulation 2002106 939-944.

7 Laughlin GA, Barrett-Connor E, Criqui MH \& Kritz-Silverstein D. The prospective association of serum insulin-like growth factor I (IGF-I) and IGF-binding protein-1 levels with all cause and cardiovascular disease mortality in older adults: the Rancho Bernardo Study. Journal of Clinical Endocrinology and Metabolism 200489 114-120.

8 Sandhu MS, Heald AH, Gibson JM, Cruickshank JK, Dunger DB \& Wareham NJ. Circulating concentrations of insulin-like growth factor-I and development of glucose intolerance: a prospective observational study. Lancet 2002359 1740-1745.

9 Rietveld I, Janssen JA, Hofman A, Pols HA, van Duijn CM \& Lamberts SW. A polymorphism in the IGF-I gene influences the age-related decline in circulating total IGF-I levels. European Journal of Endocrinology $2003 \mathbf{1 4 8} 171-175$.

10 Vaessen N, Heutink P, Janssen JA, Witteman JC, Testers L, Hofman A, Lamberts SW, Oostra BA, Pols HA \& van Duijn CM. A polymorphism in the gene for IGF-I: functional properties and risk for type 2 diabetes and myocardial infarction. Diabetes 2001 50 637-642.

11 Vaessen N, Janssen JA, Heutink P, Hofman A, Lamberts SW, Oostra BA, Pols HA \& van Duijn CM. Association between genetic variation in the gene for insulin-like growth factor-I and low birthweight. Lancet 2002359 1036-1037.

12 Geelhoed JJ, Mook-Kanamori DO, Witteman JC, Hofman A, van Duijn CM, Moll HA, Steegers EA, Hokken-Koelega AC \& Jaddoe VW. Variation in the IGF1 gene and growth in foetal life and infancy. The Generation R Study. Clinical Endocrinology 2008 68 382-389.

13 Bleumink GS, Schut AF, Sturkenboom MC, Janssen JA, Witteman JC, van Duijn CM, Hofman A \& Stricker BH. A promoter polymorphism of the insulin-like growth factor-I gene is associated with left ventricular hypertrophy. Heart $200591239-240$.

14 van Rijn MJ, Slooter AJ, Bos MJ, Catarino CF, Koudstaal PJ, Hofman A, Breteler MM \& van Duijn CM. Insulin-like growth factor I promoter polymorphism, risk of stroke, and survival after stroke: the Rotterdam study. Journal of Neurology, Neurosurgery, and Psychiatry 200677 24-27.

15 Yazdanpanah M, Sayed-Tabatabaei FA, Janssen JA, Rietveld I, Hofman A, Stijnen T, Pols HA, Lamberts SW, Witteman JC \& van Duijn CM. IGF-I gene promoter polymorphism is a predictor of survival after myocardial infarction in patients with type 2 diabetes. European Journal of Endocrinology 2006155 751-756.

16 Bleumink GS, Rietveld I, Janssen JA, van Rossum EF, Deckers JW, Hofman A, Witteman JC, van Duijn CM \& Stricker BH. Insulin-like growth factor-I gene polymorphism and risk of heart failure (the Rotterdam Study). American Journal of Cardiology 200494 384-386.

17 Rietveld I, Hofman A, Pols HA, van Duijn CM, Lamberts SW \& Janssen JA. An insulin-like growth factor-I gene polymorphism modifies the risk of microalbuminuria in subjects with an abnormal glucose tolerance. European Journal of Endocrinology $2006154715-721$.

18 Rietveld I, Ikram MK, Vingerling JR, Hofman A, Pols HA, Lamberts SW, de Jong PT, van Duijn CM \& Janssen JA. An igf-I gene polymorphism modifies the risk of diabetic retinopathy. Diabetes $2006552387-2391$.

19 Yazdanpanah M, Rietveld I, Janssen JA, Njajou OT, Hofman A, Stijnen T, Pols HA, Lamberts SW, Witteman JC \& van Duijn CM. An insulin-like growth factor-I promoter polymorphism is associated with increased mortality in subjects with myocardial infarction in an elderly Caucasian population. American Journal of Cardiology 200697 1274-1276.

20 Hofman A, Jaddoe VW, Mackenbach JP, Moll HA, Snijders RF, Steegers EA, Verhulst FC, Witteman JC \& Buller HA. Growth, development and health from early fetal life until young adulthood: the Generation $\mathrm{R}$ Study. Paediatric and Perinatal Epidemiology $2004 \mathbf{1 8} 61-72$.

21 Jaddoe VW, Mackenbach JP, Moll HA, Steegers EA, Tiemeier H, Verhulst FC, Witteman JC \& Hofman A. The Generation R Study: design and cohort profile. European Journal of Epidemiology 2006 21 475-484.

22 Weber JL \& May PE. Abundant class of human DNA polymorphisms which can be typed using the polymerase chain reaction. American Journal of Human Genetics 198944 388-396.

23 Allen NE, Davey GK, Key TJ, Zhang S \& Narod SA. Serum insulinlike growth factor I (IGF-I) concentration in men is not associated with the cytosine-adenosine repeat polymorphism of the IGF-I gene. Cancer Epidemiology, Biomarkers and Prevention 200211 319-320.

24 Frayling TM, Hattersley AT, McCarthy A, Holly J, Mitchell SM, Gloyn AL, Owen K, Davies D, Smith GD \& Ben-Shlomo Y. A putative functional polymorphism in the IGF-I gene: association studies with type 2 diabetes, adult height, glucose tolerance, and fetal growth in UK populations. Diabetes $2002512313-2316$.

25 Landmann E, Geller F, Schilling J, Rudloff S, Foeller-Gaudier E \& Gortner L. Absence of the wild-type allele (192 base pairs) of a polymorphism in the promoter region of the IGF-I gene but not a polymorphism in the insulin gene variable number of tandem repeat locus is associated with accelerated weight gain in infancy. Pediatrics 2006118 2374-2379.

26 Rietveld I, Janssen JA, van Rossum EF, Houwing-Duistermaat JJ, Rivadeneira F, Hofman A, Pols HA, van Duijn CM \& Lamberts SW. A polymorphic CA repeat in the IGF-I gene is associated with gender-specific differences in body height, but has no effect on the secular trend in body height. Clinical Endocrinology 200461 195-203.

27 Bruce S \& Alpert M. Adult/pediatric validation study of the CAS Model 740 non-invasive blood pressure monitor: AAMI SP10: 2002 Format, 2003.

28 Gomez-Marin O, Prineas RJ \& Rastam L. Cuff bladder width and blood pressure measurement in children and adolescents. Journal of Hypertension $1992 \mathbf{1 0} 1235-1241$.

29 Schiller NB, Shah PM, Crawford M, DeMaria A, Devereux R, Feigenbaum H, Gutgesell H, Reichek N, Sahn D, Schnittger I, Silverman NH \& Tayik AJ. Recommendations for quantitation of 
the left ventricle by two-dimensional echocardiography. American Society of Echocardiography Committee on Standards, Subcommittee on Quantitation of Two-Dimensional Echocardiograms. Journal of the American Society of Echocardiography 19892 358-367.

30 Devereux RB, Alonso DR, Lutas EM, Gottlieb GJ, Campo E, Sachs I \& Reichek N. Echocardiographic assessment of left ventricular hypertrophy: comparison to necropsy findings. American Journal of Cardiology $1986 \mathbf{5 7} 450-458$.

31 Teichholz LE, Kreulen T, Herman MV \& Gorlin R. Problems in echocardiographic volume determinations: echocardiographicangiographic correlations in the presence of absence of asynergy. American Journal of Cardiology 197637 7-11.

32 Reichek N \& Devereux RB. Reliable estimation of peak left ventricular systolic pressure by M-mode echographic-determined end-diastolic relative wall thickness: identification of severe valvular aortic stenosis in adult patients. American Heart Journal $1982103202-203$.

33 Gellermann J, Kraft S \& Ehrich JH. Twenty-four-hour ambulatory blood pressure monitoring in young children. Pediatric Nephrology 199711 707-710.

34 Varda NM \& Gregoric A. Twenty-four-hour ambulatory blood pressure monitoring in infants and toddlers. Pediatric Nephrology 200520 798-802.

35 Sowers JR. Insulin and insulin-like growth factor in normal and pathological cardiovascular physiology. Hypertension 199729 691-699.
36 Argente J, Barrios V, Pozo J, Munoz MT, Hervas F, Stene M \& Hernandez M. Normative data for insulin-like growth factors (IGFs), IGF-binding proteins, and growth hormone-binding protein in a healthy Spanish pediatric population: age- and sexrelated changes. Journal of Clinical Endocrinology and Metabolism 199377 1522-1528.

37 Juul A, Dalgaard P, Blum WF, Bang P, Hall K, Michaelsen KF, Muller J \& Skakkebaek NE. Serum levels of insulin-like growth factor (IGF)-binding protein-3 (IGFBP-3) in healthy infants, children, and adolescents: the relation to IGF-I, IGF-II, IGFBP-1, IGFBP-2, age, sex, body mass index, and pubertal maturation. Journal of Clinical Endocrinology and Metabolism $1995 \mathbf{8 0}$ 2534-2542.

38 Pauliks LB, Cole KE \& Mergner WJ. Increased insulin-like growth factor-1 protein in human left ventricular hypertrophy. Experimental and Molecular Pathology 199966 53-58.

39 Donohue TJ, Dworkin LD, Lango MN, Fliegner K, Lango RP, Benstein JA, Slater WR \& Catanese VM. Induction of myocardial insulin-like growth factor-I gene expression in left ventricular hypertrophy. Circulation 199489 799-809.

Received 9 May 2008

Accepted 2 June 2008 